Pedro C. Tapia Zúñiga

\title{
La magia de la hechicera de Teócrito
}

La hechicera de Teócrito, Idilios 2, y el tercer libro de la Argonáutica de Apolonio de Rodas han sido considerados, unánimemente, como paradigmas de poesía amorosa $\mathrm{y}$, en esta línea, como lo mejor que nos ha llegado de la literatura helenística. Este idilio, más que cualquier otro poema de Teócrito, invita a hablar de la magia: ya de la "hechicería" de Simeta, la protagonista del poema, ya de la "encantadora" combinación de las palabras de Teócrito.

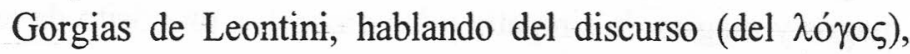
decía que "la fuerza de su encanto $(\xi \pi \omega \delta \eta ்),{ }^{1}$ sumada a las opiniones de la mente, fascina, persuade y cambia las cosas mediante la goecia $(\gamma \circ \eta \tau \varepsilon i \alpha),{ }^{2}$ y que de ésta y de la magia ( $\mu \alpha \gamma \varepsilon i \alpha)$ resultaron dos artes que son errores del ser humano, y engaños de su opinión". 3 Este pasaje de Gorgias nos introduce directamente al tema, y aunque se refiere al discurso y suena muy metafórico, debe hacernos recordar que el autor sabía de magia en el sentido estricto del término: Sátiro cuenta que Gorgias había estado presente en un encantamiento de su maestro Empédccles. Por lo demás, el pasaje es dificil en su parte

${ }^{1}$ Sobre "encanto" ( $\left.\varepsilon \varkappa \omega \delta \dot{\eta}\right)$, cf. infra, nota 19.

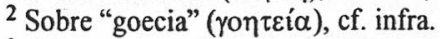

${ }^{3}$ Cf. Gorgias, Encomio de Helena, 10. Cf. Gorgias, Fragmentos (introducción, traducción y notas de Pedro C. Tapia Zúñiga), México, UNAM, Bibliotheca Scriptorum Graecorum et Romanorum Mexicana, 1980, p. 13. 
final $^{4} \mathrm{y}$, a pesar de toda su simetría, típica de Gorgias, a algunos les ha parecido mutilado. ${ }^{5}$

De cualquier manera, según Gorgias, la magia del discurso estriba en la potencia que tiene para hacernos cambiar de opinión. Teócrito, parece evidente, mediante la magia de sus palabras nos ha cambiado la opinión clásica de la mujer; se ha acercado a ella "sin el fasto de los mitos, «sin la magnificencia de los regalos, sin la intervención de los dioses. Frente a las grandes figuras de amantes de la épica, de la tragedia, de la historia, Simeta es la más humilde"; 6 sin embargo, ella no es decoración de fondo, no está creada para resaltar al héroe, sus acciones no inspiran sentimientos de culpabilidad y su capacidad de amor supera en todo al amado. Como poeta, pues, según se dice, Teócrito se defiende solo; ello y el hecho de que hay que hablar de la magia en sentido estricto, excusan de entrar al texto desde un punto de vista literario. ¿Qué puede decirse de Teócrito como mago? Muchas cosas. En las siguientes líneas me concreto a bosquejar algunos aspectos de la magia en la antigüedad (fármaco y filtros, el rito y sus partes, magos y magias, la simpatía y los dioses), a propósito de este idilio. $^{7}$

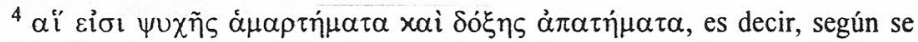
tradujo, "que son errores del ser humano ( $\psi v \chi \tilde{\eta} \zeta)$, y engaños de su opinión".

${ }^{5}$ De acuerdo con el suplemento de Pohlens (Aus Platos Werdezeit, p. 40), hay que entender: "De la goecia y de la magia han resultado dos artes de las cuales una, mediante fármacos, realiza cambios que obedecen a las debilidades del cuerpo y a las enfermedades de la carne, y otra, mediante palabras, produce pensamientos novedosos que son errores del ser humano y engaños de su opinión". Magia, pues, en el primer caso, mediante fármacos, y goecia, en el segundo, mediante palabras; y no está mal; pero siento que se reduce un poco el concepto de magia. Yo entiendo que Gorgias, mediante errores de la $\psi u \chi \dot{\eta}$ se refiere a todo tipo de magia (toda magia es un camino equívoco del ser humano), y mediante engaños de la $\delta o ́ \xi \alpha$ se refiere a la magia de los discursos, de cualquier tipo, capaz de manipular la opinión del ser humano, siempre lejos de la verdad.

${ }^{6}$ Cf. Dánae Frangos Mayorga, "Los idilios de Teócrito", México, UNAM, Facultad de Filosofia y Letras 1963 (tesis de maestría), p. 8.

7 Para mayor información sobre los elementos estrictamente mágicos de este idilio, puede recurrirse fácilmente a los eruditos y detallados comentarios 
Ya el título mismo del poema, ФAPMAKEYTPIA, la hechicera ${ }^{8}$ obliga a una primera observación sobre el tema, y no precisamente acerca de una de las controversias tradicionales, sino sobre el significado de las palabras $\varphi$ í $\tau \tau \rho \nu$ y $\varphi \alpha ́ \rho \mu \alpha-$ xov; de ésta se deriva $\varphi \alpha \rho \mu \alpha x \varepsilon v ́ \tau \rho ı \alpha$, y con ella están emparentadas otras semejantes, como farmakeia, farmakéuo y, en español, farmacia. Filtron, en el texto, se tradujo mediante "filtro", y fármacon, mediante la palabra "veneno". Ahora bien, cada una de estas palabras (filtron y fármacon) aparece dos veces dentro del poema, y su uso, si no es problemático, por lo menos resulta curioso. Simeta, en el verso 1, pregunta por sus "filtros", ¿dónde están?; y en los versos 14 y 15, después de invocar a Hécate, le suplica que haga los "venenos" que va a preparar, tan potentes como los de Medea, Circe y Perimeda. Sin embargo, después de que nuestra farmaceuta ha terminado sus horrendas prácticas venenosas y sus dulces lamentos, dice, dirigiéndose a la Luna, "ahora voy a embrujar$10^{10}$ con estos filtros". Si dijo que iba a preparar venenos, ¿por qué al final nos sale con filtros? Y en seguida, el caos parece tomar forma; si mi Delfis no regresa, se va a ir al diablo: "afirmo reservarle dentro de un arca fuertes venenos, mortales..."11

de A. S. F. Gow, Theocritus (edited with a translation and commentary), vol. II, pp. 33-63.

${ }^{8}$ Este poema de Teócrito, ФAPMAKEYTPIA, podría llamarse, literalmente, La farmaceuta.

${ }^{9}$ Las referencias a los versos se hacen de acuerdo con la traducción presentada en "La hechicera de Teócrito", de Felipe Sánchez Reyes y Pedro C. Tapia Zúñiga; dicha traducción, como ahí se indica, sigue el orden que propone Gow, op. cit., vol I, pp. 16-28.

10 Se trata del verso 159. Véase el verso 10: "Ahora, voy a embrujarlo sahumando inciensos"; cf. verso 3, donde también se usó la palabra "embrujar". Si se quiere, el verbo "embrujar" no es exacto; se trata del verbo griego katadéomai, literal: ligar, amarrar; en griego, dicho verbo es una palabra íntimamente ligada a los objetivos de la magia. El lector dirá si le gusta aquí la palabra "embrujar", en lugar de la de ligar o amarrar, que sería más "literal".

11 Cf. verso 161-162 de la traducción; en el griego no existe la palabra "mortales", pero se deduce fácilmente del verso 160: "él pronto irá a llamar, juro a las Moiras, la puerta de Hades", y es un refuerzo al adjetivo "fuertes" con que 
Es casi del dominio público que en la antigüedad, exceptuando el uso normal de filtros medicinales, como el vino, al hablar de filtros se sobreentendía "amorosos", y se los relacionaba con la magia de ese tipo; se trataba normalmente de substancias líquidas elaboradas a base de vegetales o animales. Por el contrario, el fármacon originalmente es algo püramente ligado a la magia, y aunque la palabra significa "veneno", se trataba de un ingrediente mágico en general; ya posteriormente, la medicina hipocrática conoce el fármaco, y aquí, en medicina, normalmente se trataba de medicamentos vegetales. ${ }^{12}$ Cabe pensar, pues, que el fármaco va de lo más o menos venenoso, hasta lo mortal, mientras que el filtro se restringe a producir ciertos efectos amorosos.

Sobre la práctica, las cosas no parecen muy claras, por lo menos en nuestra hechicera. Ella, como se anotaba anteriormente, pide sus filtros; excelente: piensa en ciertas prácticas de magia amorosa. Pero, poco después, dice que va a preparar un fármaco; y después de preparar sus fármacos, dice que va a embrujar a Delfis con filtros. Más que pensar en un descuido de Teócrito, puede verse su malicia y la poética ingenuidad con que nos pinta a una joven hechicera que desconoce los términos o que, como nosotros, se confunde con ellos. Teócrito no era un mago, pero, al menos por lo que demuestra su poema, conocía los rudimentos del arte; según se verá en seguida, las acciones de Simeta, particularmente aquellas que constituyen la primera de las dos partes del mimo, reúnen ortodoxamente todos los elementos de un rito de magia.

Un rito mágico, según sabemos, ${ }^{13}$ constaba de cuatro elementos: invocación, ofrenda, praxis y amuleto. Los papiros

se calificó a los venenos, y que parece débil ante el griego xaxá, "malo", mucho más expresivo que "fuerte".

12 Cf. Kudlien, Kiel, en Kl. P., s.v. Pharmakologie, y W. Artelt, Studien zur Geschichte der Begriffe "Heilmittel" und Gift, Leipzig, 1937. Reimpr., 1968.

${ }^{13} \mathrm{Cf}$. Hopfner, en $R E$, s.v. Mageia, 301-391; en especial, para las partes del rito mágico, cf. 364,41 y ss. 
mágicos griegos ${ }^{14}$ dicen, describiendo el rito, que primero hay que hacer la ofrenda, luego la invocación; después sigue la praxis propiamente dicha (haz esto y lo otro), y finalmente, dicen, no hay que olvidarse del amuleto, el cual debe ser de este y del otro tipo. Naturalmente, todo el rito es una praxis; y quizá valga ilustrar la praxis propiamente dicha (uno de los cuatro elementos del rito), recurriendo a nuestro poema que, como se apuntaba anteriormente, contiene todos los elementos.

Se trata, en la praxis propiamente dicha, de qué hay que hacer en concreto: nuestra hechicera dice expresamente, "se consume, primero, cebada en fuego" (vv. 18-19); en seguida, "ahora, por Delfis, quemo laureles" (vv. 23-24); luego, "voy a quemar salvado" (vv. 28-29); a continuación, "yo, con la diosa derrito aquí este céreo muñeco" (vv. 38-39); ahora, "una planta arcadia, muy lujuriosa"; 15 adelante, "esta franja inferior del manto suyo perdió mi Delfis; / ahora, haciéndola trizas, al fuego cruel yo se la arrojo" (vv. 53-54), y finalmente, "triturando un lagarto, fuerte brebaje llevo mañana; / pero ahora, Testilis, tú toma y suave frota estas hierbas" (vv. 58-59). Por supuesto, sólo se ha hecho una enumeración, y resultaría más interesante ir al detalle en busca del porqué y para qué de cada uno de dichos materiales y prácticas. Esto no cabe en unos apuntes generales, ${ }^{16}$ valga decir, por un lado, que en gran parte se desconoce la relación concreta que existe entre esos

${ }^{14}$ Cf. Textos de magia en papiros griegos (Intr., trad. y notas de José Luis Calvo y Ma. Dolores Sánchez Romero), Madrid, Gredos, 1987. Cf. Hopfner, ib., 301-302.

${ }^{15}$ Hippomanés, dice el griego; literalmente, "que enloquece a tos caballos". "Coltsfoot is an Arcadian weed", dice Gow en su traducción, op. cit. vol. I, p. 19. Cf., si se quiere, Dover, K. J., Teocritus: Select poems, Macmillan Education LTD, Glasgow, 1971, y Virgilio, Geórgicas, 3, 280.

${ }^{16}$ Cf. Dover, op. cit., p. 105; Decia, Giovanni, "Sull' idilio di Teocrito intitolato farmakeutriai", en Rivista di Filologia e di Istruzione Clasica, 1897, pp. 257-283; Eitrem, S., "La magie comme élément littéraire chez grecs et romains", en Symbolae Osloenses, 21, 1971, pp. 31-83; Bignone, Ettore, "La 'Fatura', un mimo d' amore di Teocrito", en Dionisio, 4, 1933, pp. 1-25; y también, Frazer, J. La rama dorada (Tr. de Elizabeth y Tadeo I. Campuzano), México, FCE, 1969. 
ingredientes tanto vegetales como animales, y los efectos que se supone han de producir, y por el otro, que teóricamente puede decirse de ellos lo que se dirá más adelante sobre los amuletos, a propósito de la simpatía.

El orden, y las partes del ritual propuesto por los papiros mágicos, no es uniforme; suena antropológicamente normal, en el trato con los dioses, ofrecerles algo antes de-suplicarles algo. Teócrito lo sabe, pero nuestra joven hechicera parece olvidarlo: desde el principio del verso 10 habla de inciensos, pero sólo se trata, según el futuro que usa, de una promesa. La ofrenda tendrá que esperar hasta los versos 28 y 43, donde, respectivamente, se ofrecen salvado y vino.

Aunque es normal, pues, comenzar con la ofrenda, a veces, como en nuestro idilio, precede la invocación: "Vamos, alumbra, / Luna, con gran fulgor. Diosa, en voz baja voy a invocarte", y luego: "Hécate horrenda, salve; por esta noche sénos propicia", cf. vv. 11-14, lo cual, creo, en uno y en otro caso equivale a un "ven y hazte presente". Hay, por lo menos, dos tipos de invocaciones (fórmulas mágicas, súplicas, logos, en general): unas, como ésta con que empieza Simeta, son las verdaderas fórmulas; pretenden seducir a los dioses, o llamar su atención, u obligar su presencia; lograda la presencia de los poderes superiores, lo demás es fácil. Otras fórmulas son las que expresan el verdadero deseo del mago: "ave de amor, ${ }^{17} \mathrm{al}$

17 "Ave de amor", traduce la palabra griega Iynx que, en mitología, "es' una ninfa hija de Eco y de Peitho, que por medio de sus hechizos captura el amor de Zeus para to o para ella misma, y en venganza es transformada por Hera en piedra o en el ave iynx, descrita como ave del cuello retorcido o torcecuello", cf. Felipe de Jesús Ricardo Sánchez Reyes, "El idilio II de Teócrito: introducción, traducción y notas", México, UNAM, Facultad de Filosofía y Letras, 1994 (tesis de licenciatura) pp. 55-56. Para el ave, cf. Aristóteles, Historia de los animales, 504a 12 y ss.; Plinio, Historia natural, 11, 256, etcétera; vid. Will Richter, en $\mathrm{Kl}$. $P .$, s.v., Wendehals. Más información, en Gow, A. S. F., "Ĩ $\mathrm{I} \gamma \xi \xi$, Rhombus, Turbo", en Journal of Hellenic Studies, 54, 1934, pp. 1-13; Segal, Charles, "Simaeta and the l' iynx (Theocritus, Idill II)", en Quaderni Urbaniti, 15, 1973, pp. 32-43. 
joven aquel arrastra tú hasta mi casa". ${ }^{18}$ Incluso se sabe, y quizá era lo más frecuente, que al llamado de los dioses seguían otras muchas fórmulas (acompañadas de ofrendas), cuando el invocado no reaccionaba a la primera súplica. Por cierto, todo rito mágico normalmente se cierra con otra fórmula, la de la despedida (apólysis), de la cual se dirá algo al final de estos apuntes.

Era normal, creo, que los poderes superiores no reaccionaran a la primera súplica. A nadie le gusta ser esclavo de nadie, y menos, a los inmortales. El mago, según se pensaba, tenía el poder de coaccionar, de obligar a los dioses, tanto para que hicieran acto de presencia, como para que se fueran de regreso, cosa que, por supuesto, no resultaba graciosa ni para los dioses ni para los demonios que, por lo mismo, odiaban a los magos. Precisamente por esto, Lucano dice de la magia que es un secreto, propiedad del cruel mago y repugnante a los dioses. ${ }^{19} \mathrm{El}$ mago, por tanto, debía temer la furia de los demonios, y protegerse con un amuleto. Nuestra hechicera nota la presencia de la divinidad, y se dirige a su ayudante, quizá casi en secreto, para no malograr su rito: "Testilis, ya las perras aúllan en la urbe por nuestra magia; / la diosa está en los cruces de las vías"; inmediatamente se acuerda de su amuleto y, quizá toda excitada, le grita a Testilis: "pronto, tañe tú el bronce" (vv. 30-31). ${ }^{20}$

${ }^{18}$ Más adelante se ven fórmulas de deseos más concretos: "De Delfís ahora vierto los huesos", vv. 21 y 61; "Delfis, sí, consumiera su carne en llamas", v. 26; "se derritiera Delfis el mindio", v. 39; "muchas vueltas se diera frente a mi casa", v. 41; "un olvido terrible", v. 45 , etcétera.

${ }^{19}$ Cf. Lucano, Farsalia, VI, 430-434: Ille supernis / detestanda deis saevorum arcana magorum / noverat. De la violencia de la magia se ha dicho que

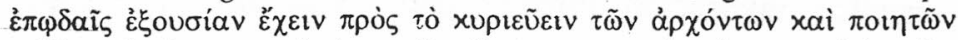

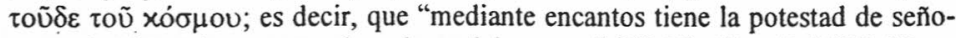
rear sobre los gobernantes y hacedores del cosmos". Cf. Hipólito, Ref. VII, 32.

${ }^{20}$ Los metales adquirieron un mayor significado mágico gracias a la astrología; para metales, cf. Hopfner, ib., 326-327; especialmente sobre Teócrito, 326, 37-43; para amuletos, cf. también, Villeneue, Rolland, El universo diabólico (traducción de José Lasaga), Madrid, editorial Abraxas, 1976. Cf. infra. 
Ante la fuerza del amuleto, de buen o mal grado, todos se someten: dioses y demonios, superiores o inferiores, toda la creación. ${ }^{21}$ La potencia de los amuletos, igual que la de los fármacos y filtros, en el terreno de la magia se explicaba o se pretendía explicar mediante la teoría de la simpatía; esto es, por la mayor o menor relación que existe entre lo creado, entre todo el universo. De ello se dirá algo más adelante. Si servía el amuleto, si el mago lograba sus objetivos después de la praxis...

Se dicen tantas cosas, se cuentan tantas otras, que, como unas veces uno está tentado a creer, otras, quizá en la mayoría de los casos (exceptuando la colación de venenos, los fenómenos parapsicológicos y las técnicas de ilusionismo), el resultado que se deseaba (un milagro o algún suceso natural), como dice Kleinfeller, o bien no sucedía o, si sucedía, no tenía ninguna relación objetiva con las prácticas del hechicero; de manera que, para empezar, la "magia" puede describirse como una simulación de fuerzas sobrenaturales con fines ilícitos, y el "mago", como un hechicero mal intencionado. ${ }^{22}$ Pero, ¿puede decirse eso de todos los magos? ¿Quién es un mago? ¿Qué hay que entender por magia?

La magia es el arte de los magos; y originalmente, los magos son una casta sacerdotal persa, ${ }^{23}$ más bien religiosa, que, según decían algunos griegos, sabían de todo, menos de magia, como se entendió después y hoy la entendemos. De allí, de Persia, los griegos tomaron tanto el arte como el nombre mismo (magia), y nos transmitieron prácticamente todo lo que se sabe sobre el tema. Más tarde, el uso y la costumbre mezcló indisolublemente esta magia de los iranios con las prácticas hechiceras, astronómicas, adivinatorias y astrológi-

${ }^{21}$ Cf. san Clemente de Alejandría, Protréptico, XI, 115 (Sources Chrétiennes, 1976, pp. 183-184) y, en general, Hopfner, ib., 336-337.

${ }^{22}$ Cf. Kleinfeller, en $R E$, $(14,1)$, col. 396.30 y ss.

${ }^{23}$ Más o menos como la de los druidas, entre los celtas. 
cas de los caldeos (después babilonios), y ya en la época helenística, bajo el gran influjo de Oriente, cualquier escrito de alquimia, magia o astrología, si pensaba en el éxito, debía aparecer bajo la autoridad de alguno de aquellos orientales, como Zoroastro, el fundador de la religión de los persas. ${ }^{24}$

Nada de esto significa que los griegos no hübieran conocido ciertas prácticas mágicas antes de los tiempos sincréticos (siglos v y IV a. C.: las guerras médicas); sin embargo, según puede verse en los poemas de Homero, tales poderes y fuerzas sobrenaturales eran, en general, propiedad de los dioses: en la Ilíada, 14, 214 y ss., se habla de un cinturón mágico, pero dicha prenda está en las manos de Afrodita. ${ }^{25}$ Las leyendas de héroes ya saben de hechicería; recuérdese, por ejemplo, a la Medea de Sófocles, y a la de Eurípides; el llamado del alma de Darío en los Persas de Esquilo, y el uso hechicero de alguna prenda del amado en el Hipólito de Eurípides. Lo cierto es que, ante la sabiduría y el arte de los magos persas, los griegos se quedaron mudos, y al tiempo que dieron a ese arte el nombre de magia, aplicaron este mismo nombre a todo lo que entra en el terreno de la hechicería y prácticas que ellos ya conocían.

¿Qué hacen los magos, qué hace la magia? Para terminar pronto, digamos que hacen de todo, ${ }^{26} \mathrm{y}$ es posible, aunque complicado, dividir la magia de acuerdo con lo que hace, de acuerdo con los efectos que produce o dice poder realizar. Algo de lo que puede la magia es lo que busca nuestra hechicera: embrujar, ligar, enyerbar al amado, y el poema de Teócrito (al fin y al cabo un mimo) se encarga de imitar y recrear lo sombrío y misterioso de esos ritos: "Diosa, en voz baja, voy

24 Cf. J. Duchesne-Guillemin, en $K l$. P., s.v. Magoi.

25 Véase también, iliada, 13, 22 y 24, 343. Odisea, 10, 210 y ss.; 12, 40; incluso aquí, en la Odisea, algunos hombres ya saben de magia; cf. 10, 510 y 11, 22.

${ }^{26}$ Hopfner, ib., 375, 17 - 378, 2, citando a Georgii; véase también, a manera de ejemplos, Éxodo, 7 y ss., y Séneca, Medea, 740 y ss. 
a invocarte" (v. 10); "y siniestra murmura: de Delfis ahora froto los huesos" (v. 61). Lo más seguro es que Simeta trabaje fuera de la ciudad: " $¡ T e s t i l i s$, ya las perras aúllan en la urbe por nuestra magia; / la diosa está en los cruces de las vías" (vv. 30-31); sin duda opera de noche y a la luz de la luna, ${ }^{27}$ etcétera. Esa omnipotencia de la magia, unida al ambiente nocturno, macabro y misterioso que rodea sus prácticas, la hicieron merecedora de los peores epítetos.

A lo misterioso y sombrío del rito hay que añadir el celo con que los magos guardan sus secretos y fórmulas, y los protegen del vulgo; y si alguien piensa que todo este ambiente de soledad misteriosa y aislamiento oficial está en función de protegerse de las miradas críticas y cuidarse de persecuciones legales, así como de embaucar más fácilmente a los ingenuos, no está lejos de la verdad. No obstante, y a pesar del desprestigio general de la magia, ya desde la antigüedad se distinguía entre magos y magos, magias y magias, dejando fuera de la cuestión y casi sólo como punto de referencia a la magia original, el arte de los magos persas.

Dejando a un lado, pues, la magia de los persas (sin que esto signifique que ella estaba totalmente exenta de hechicería), pueden distinguirse, recordando a san Agustín, tres tipos de magias, de las cuales, dos son totalmente opuestas: la "teúrgia" y la "goecia"; en medio de ellas estaría, al centro, la "magia en sentido estricto". La goecia, dice san Agustín, es la peor de las magias; la teúrgia, la más sublime. ${ }^{28}$ Las tres, como magias, se parecen en algo, y en algo se distinguen. A

${ }^{27}$ Quizá, exagerando el detalle, uno podría imaginarse la luna de los enamorados (la de Acuario), o la más apta para obligar (la de Aries), o la que liga necesariamente (la de Leo), y no creo necesario entrar al porqué de estas atribuciones; cf. Hopfner, ib. 335, 45 y ss.

${ }^{28}$ magia vel detestabiliore nomine goëtia vel honorabiliore theurgia; cf. san Agustín, de civ. Dei, X, 9, y continúa: "los que pretenden distinguir estas ridiculeces, quieren dar a entender que de los que se entregan al estudio de las artes ilícitas, unos son reprensibles, cuales son los que el vulgo llama maléficos o hechiceros, porque éstos dicen que pertenecen a la goecia, y otros, más loables, a 
las tres les es común tanto la violencia que ejercen sobre los poderes superiores, como la búsqueda de efectos que están fuera de lo normal; sin embargo, se distinguen, por una parte, en la clase de efectos que se proponen; por la otra, en la manera como influyen sobre los poderes superiores, y finalmente, en los tipos de violencia a que recurren. La división obedece, en general, al tipo de poderes superiores de que se valen para conseguir los efectos deseados: teóricamente, la teúrgia sólo recurre a los demonios más sublimes, e incluso a los dioses, todos elevados más allá de la materia; la magia (en sentido estricto) a los demonios, materiales e inmateriales, y la goecia, solamente a los demonios materiales, impuros y maléficos.

Cada uno de estos demonios y dioses tiene un nombre, y el "nombre" merecería algo más que un párrafo. Simplificando las cosas, baste apuntar que la potencia del mago es ilimitada, cuando llega a saber el nombre del demonio que le interesa. Quien sabe el "verdadero" nombre, tiene los ases en la mano. Ante el nombre propio, que por influjos del Oriente se identifica con la inalienable esencia del dios o de la cosa nombrada, el invocado no tiene más que someterse al arbitrio del mago. Por ello, saber el nombre es el gran secreto profesional, el máximo grado de la sabiduría mágica; se prohibe pronunciarlo, y se recurre a mil artificios matemáticos y fonéticos para decir el nombre sin pronunciarlo. ${ }^{29}$

quienes atribuyen la teúrgia, siendo indubitable que unos y otros están sujetos y dedicados a los falsos y engañosos ritos de los demonios, bajo los nombres de ángeles".

${ }^{29} \mathrm{El}$ dios o el demonio (lo saben éstos y lo sabe el mago) no pueden resistirse ante su nombre; este hecho se prestaba a juegos increíbles que podríamos ejemplificar en el siguiente parlamento: "si no vienes, digo tu nombre, y para que sepas que sé tu nombre, aquí te va en clave: tú eres el demonio x y $\mathrm{z}$; ven, o lo pronuncio". Y la clave podía ser fonética (pensemos en el popular abracadabra,

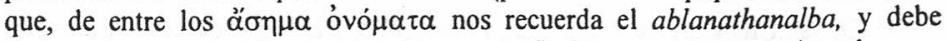
interpretarse de acuerdo con una clave específica) o numérica: por ejemplo, y es un simple invento, para amenazar a Hécate, démosle a cada letra de su nombre el valor numérico normal que les corresponde en griego, y finjamos la aspiración 
Esta división de la magia, basada en la tipología de los poderes superiores, puede parecer artificial; sin embargo, responde a hechos objetivos, dentro del arte de la magia: al fin y al cabo, sin dioses ni demonios no serían posibles ni explicables los poderes del-mago ni, por lo mismo, la existencia de la magia. Sobre ello, creo, es necesario decir algo más adelante.

¿Y de nuestra hechicera, cuál es su magia? Buena pregunta; pero la respuesta no es sencilla. Apuntemos, por ahora, una salida fácil: ella invoca a la Luna y se encomienda a Hécate; aquélla es una divinidad secundaria, pero Hécate es un horrendo demonio, de lo peor. Sobre la práctica, si damos como válido el título del poema, farmakeutria, uno puede decir que Simeta trabaja con la farmakeia, un subgénero de la magia definido como "una práctica que recurre a las comidas y a los brebajes", ${ }^{30}$ y así, estrictamente, una especie de la goecia. Más adelante, espero, quedarán mejor ubicadas las prácticas de Simeta.

De acuerdo con Nicéforo Grégoras, la teúrgia no pertenece a la magia; ello nos da una idea de la, en general, alta reputación de que gozó ese tipo de magia, pero también debe hacernos conscientes de que las cosas no son tan simples, ni en la teoría $^{31}$ ni en la práctica. Aunque teóricamente, de acuerdo

mediante el valor de la letra "pi"; entonces le podemos decir al demonio de Hécate (suponiendo que ése es su verdadero nombre): "ven, yo te conozco, tú eres el demonio $80+5+20+1+300+1$ ", etcétera.

${ }^{30}$ Para magia, goecia y farmakeia, cf. Nicéforo Grégoras (Scholia in Synes-

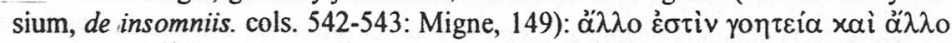

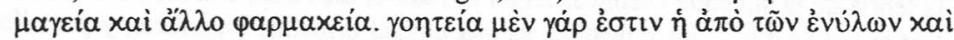

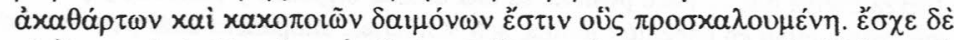

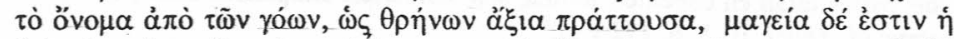

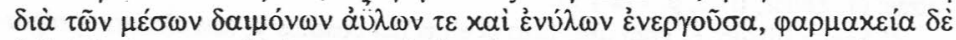

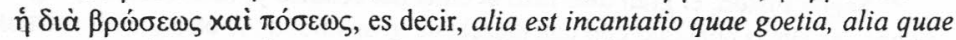
magia, et alia quae pharmacia dicitur a Graecis. Est enim goetia ratio quosdam materiae immistos, impuros et maleficos daemonas invocandi. Nomen autem

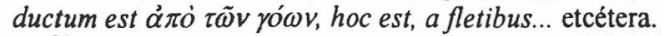

${ }^{31}$ Nicéforo habla de la farmakeia como de un género de magia, no como de un subgénero. 
con estos esquemas, parece simple definir o determinar cualquier tipo de magia (bastaría con preguntarle al mago a qué dioses o demonios se encomienda, y sabríamos cuál es su magia), sobre la práctica, las variantes son múltiples y, lo más aberrante, casi nunca se dieron puras; por lo mismo, lo que resulta definitivo es, por una parte, la personalidad del mago que define los medios, los métodos del procedimiento, y por la otra, sus intenciones personales, muchas veces inconfesables.

Hopfner propone que todas las prácticas mágicas pueden reducirse a cuatro grandes grupos de acuerdos con los efectos que intentan producir: a) magia de protección y defensa (magia en sentido estricto: mántica); b) magia de ataque y daño (la goecia); c) magia de amor y poder (la hechicería, es decir, la farmakeia), y d) magia de conocimiento y revelación (la teúrgia). ${ }^{32}$ Teóricamente, si se quiere determinar el tipo de magia, simplemente hay que preguntarse por las intenciones del mago; y nuevamente, sobre la práctica, es frecuente que se mezclen las intenciones, los procedimientos y los poderes. La teúrgia, por ejemplo, tenía las intenciones más sublimes: contemplar o hacer contemplar a dios, y su método era nobilísimo, la gnosis. ${ }^{33}$ sin embargo, se sabe de teúrgos que, para llegar al fin, descuidaron el método, y recurriendo a otros medios, cayeron en la magia en sentido estricto. Ésta, en general, recurre a demonios de rango mayor, e incluso a los dioses; usa materiales simpatéticos (amuletos) que caracterizan a la teúrgia que, como ya se apuntaba, supone conocimientos precisos de las relaciones que hay entre lo invisible y lo visible. Con intenciones de protección y defensa, busca adivinar el futuro, una especie de revelación, mediante vías que, para

32 Cf. Hopfner, ib. 378, 3 y ss.

${ }^{33}$ Entre los teúrgos más notables hay que recordar a los neoplatónicos Plotino, Porfirio, Jámblico, Heresco y Damascio; de Jámblico puede leerse, sobre todo, De mysteriis. Para lo que san Agustín piensa de los teúrgos, cf. supra, nota 28. 
decirlo rápidamente, podrían calificarse como "alucinatorias", y forman gran parte de las artes mágicas que terminan en -mancia, como, por ejempo, la licnomancia, hidromancia, lecanomancia, fialomancia, esquifomancia, catoptromancia, necromancia, etcétera, y todas las formas de posesión, en donde ya no intervienen los dioses supremos, sino los demonios y las almas de los muertos ${ }^{34}$ que se revelan a través de algún medio.

Cuando el medio se hace totalmente mecánico y material (sin la menor mística posible), ya estamos en el terreno de la goecia, la adivinación mecánica, de cuyas prácticas Artemidoro hace un buen resumen. ${ }^{35}$ La goecia, puesta al servicio del amor y del poder, se convertía en hechicería, es decir, en farmakeia.

Pero, ¿qué tienen que ver con la magia los dioses y los demonios, los minerales y los vegetales, las plantas y los animales? Todo. Recapitulando ideas acerca del destino, Plutarco o un Pseudoplutarco decía: "lo más importante y principal es

34 Aquí cabría apuntar algo sobre las almas y sobre los muertos. Sobre las almas baste remitir al Timeo de Platón, y deducir las consecuencias astrológicas, simpatéticas o antipatéticas; acerca de las almas de los muertos hay que recordar que ellas eran consideradas como "falsos" demonios, aptos para ver y predecir el futuro. Como inmortales, antes de llegar a algún otro lugar, rondaban su cuerpo con más o menos persistencia de acuerdo con su naturaleza y, sobre todo, de acuerdo con la manera y el tiempo en que habían muerto. Los cuerpos de los niños eran un material hechicero muy codiciado, y no sólo se profanaban sus tumbas, sino incluso se habla de asesinatos para prácticas de necromancia: se creía que su cuerpo, poco expuesto a los apetitos del alma, era, como microcosmos, un reflejo puro del macrocosmos y sus leyes. Los hechiceros también rondaban cuerpos y tumbas de quienes habían muerto jóvenes, o no casados, o muertos por violencia, o insepultos, etcétera; sepulcros de cuerpos cuyas almas rondaban persistentemente sus cuerpos merced a que, de alguna manera, no se habían ido satisfechas, sino deseando algo que les debía la vida. Por esa estrecha relación del alma con el cuerpo, no sólo se buscan los cuerpos, sino también, incluso en vida, las cosas, prendas y lugares que habían estado (o estaban) en contacto con el cuerpo; ello explica un poco los versos 53 y 54 de nuestro poema: "esta franja inferior del manto suyo perdió mi Delfis; / ahora, haciéndola trizas, al fuego cruel yo se la arrojo".

${ }^{35}$ Fisiogmantes, astragalomantes, tiromantes, cosquinomantes, morfoscopas, quiromantes, lecanomantes y nequiomantes; cf. Artemidoro, en el prólogo a su Onirocriticus I, citado por Hopfner. 
el que nada llega a ser sin causa, sino según las causas antecedentes; segundo, el que este cosmos, estando animado por el mismo soplo y siendo 'simpático' consigo mismo, es gobernado por la naturaleza, y tercero, las cosas que más bien parecen ser testimonio respecto a esto: la mántica, entre todos los hombres bien reputada como realmente coexistente con dios..." ${ }^{36}$ En el universo, que es un ser animado e inteligente, todas y cada una de sus partes están relacionadas entre sí; es decir, viven en "simpatía", como el cuerpo humano con relación a sus partes, y por ello, lo que le sucede a una parte repercute en el todo, y el todo sufre lo que le sucede a cada parte. La causa, el antecedente de todo, es el gran dios que hizo todas las cosas, las visibles y las invisibles, con la misma pasta: a las almas y a los dioses secundarios (astros y planetas) que en seguida se encargaron de crear y de cuidar todo lo demás. ${ }^{37}$

La demonología llegó de Oriente, y Platón la hizo famosa y clara al definir a los demonios como seres intermedios, seres que viven entre el cielo y la tierra. ${ }^{38}$ Hasta antes de Platón, puede decirse que los griegos no distinguían entre fantasmas, ${ }^{39}$ demonios y almas de los muertos (a las cuales, igual que a los dioses, se les solía llamar "demonios"); todo era casi

${ }^{36}$ Plutarco, De fato, 11. Cf. Plutarco, Acerca del destino (introducción, traducción y notas de P. C. Tapia y M. Bojórquez), México, UNAM, Bibliotheca Scriptorum Graecorum et Romanorum Mexicana (en prensa). En la nota 219 se lee: "animado por el mismo soplo y siendo simpático consigo mismo... Mediante 'animado por el mismo soplo' se tradujo sympnoun; con 'simpático', se alude a la teoría de la simpatía cósmica, según la cual, el universo, a causa de esa única fuerza divina que lo hace posible, es una unidad orgánica y perfecta, y por ello sus partes están en conexión íntima, son solidarias, simpáticas unas para con las otras; cf. Zeller, III 1, p. 172 y ss."

${ }^{37}$ Según Platón, el gran dios hizo el alma del cosmos y, con distintas proporciones, las almas humanas con una mezcla de lo mismo, de lo otro y de la esencia (intermedia); hizo el cosmos, a los dioses (secundarios), y éstos al hombre, con fuego, tierra, agua y aire. Cf. Platón, Timeo, 29 y ss., y Plutarco, De fato.

${ }^{38}$ Cf. Platón, Simposio, 202.

${ }^{39}$ Empusas, lamias, estrigos, nomos, accos o cocos, alfitos... 
lo mismo, y para los magos, un instrumento esencial, junto con los dioses. ${ }^{40}$

También fue Platón quien atribuyó a los demonios una función mediadora entre el más allá y el acá, entre el cielo y la tierra, entre dios y los hombres; ${ }^{41}$ sin embargo, fueron sus alumnos (Filipo, Jenócrates, Porfirio, Jámblico, Proclo, etcétera) quienes perfeccionaron esa doctrina y le dieron lujo de detalle. Porfirio asentó que los demonios proceden del alma del mundo; Jenócrates, recordando a Demócrito, los dividió en buenos y malos, y Proclo los clasificó en series detalladísimas que, entrelazadas, permitían que los demonios subieran y bajaran del cielo a la tierra, llenando ese hueco insalvable entre lo divino y las criaturas mortales; entre lo insensible y lo sensible; entre lo celestial y lo terreno. Mediante esos seres intermedios, lo divino, que está en todas partes, penetra hasta las regiones infralunares (lo terreno y mortal) sin limitarse a ninguna de ellas. Al principio de cada serie está el gran creador, un ser inteligible, pero no visible; siguen los dioses visibles: las estrellas fijas y los planetas, y de cada uno de éstos, los demonios intermedios.

Así, de cada dios secundario, de cada planeta, según lo que cada uno haya creado en el mundo, surgen series de demonios $^{42}$ que son y se comportan de acuerdo con las características de su creador inmediato. Su inteligencia y fuerza se explican esencialmente por la mayor o menor cercanía al hacedor, igual que, a la inversa, su irracionalidad y materialidad obedecen a su cercanía al mundo material: hombres, animales, plantas y

40 Sobre todo la trinidad "Hécate-Artemis-Luna" de que, dados los objetivos de estas observaciones, no se apuntará más que su gran importancia dentro de la magia. Nuestra hechicera lo sabe, y no lo olvida; cf. "Hécate horrenda, salve; por esta noche sénos propicia"; poco después: "diosa Artemisa, mover podrías las férreas puertas de Hades, incluso habiendo cualquier cerrojo", y casi al principio del poema: “ $\mathrm{iVamos,}$ alumbra, Luna, con gran fulgor!; Diosa, en voz baja voy a invocarte".

${ }^{41}$ Cf. Platón, Timeo, 40.

42 Ángeles, arcángeles, demonios y héroes. 
minerales. Hay, por tanto, demonios del éter, del fuego, del aire, del agua y, finalmente, demonios de la materia, corpóreos, por llamarlos de alguna manera: con muy poca, casi nula capacidad intelectual, materiales, pero, al fin y al cabo, demonios; y lo que es más importante, son los protectores y conservadores de la simpatía, y los que, en última instancia, tienen el poder de iniciar $y$, naturalmente, de establecer la comunicación entre mortales e inmortales.

Quien conoce al demonio de esta planta, de aquel animal, de un X metal, puede, gracias a las series en que están dispuestos tales seres, llegar hasta los demonios intermedios y a los grandes demonios, e incluso obligarlos de alguna manera. Por eso, Jámblico decía que sabio es aquel que conoce el parentesco de las diversas partes del cosmos, pues a cada dios intermedio le está cercana una piedra o una planta, y él, a consecuencia de la simpatía, cede y está bajo el influjo del encantamiento correspondiente a cada una de éstas.

A pesar de las precisas indicaciones y proporciones ${ }^{43}$ que da el Timeo sobre la mezcla con que el gran dios hizo a las estrellas, no conocemos la esencia de la pasta final, a fin de saber sus cualidades, pero la imaginación se encargó de atribuirles mitológicamente alguna especialidad material y anímica que se convirtió en su esencia y de la cual depende que sean así o asá, y gusten de esto o de lo otro, aborreciendo lo que les es contrario. Naturalmente, las propiedades de los dioses secundarios (de las estrellas) no sólo obedecen a mitos, sino que la astronomía se ocupó de atribuirles otras propiedades, ${ }^{44}$ y como consecuencia, los minerales se llenaron de significado

${ }^{43}$ Léase el interesante estudio que César González Ochoa hace sobre el tema en La música del universo, México, UNAM, Instituto de Investigaciones Filológicas, 1994 (Cuadernos del Centro de Estudios Clásicos, 33); sobre todo, pp. 21 y ss.

44 A cada planeta le corresponde, porque fue su creador, un determinado animal, una planta, una piedra y un metal: a Saturno le corresponde el plomo; a Marte, el fierro; al Sol, el oro; a Venus, el bronce; a Mercurio, el zinc; a la Luna, 
mágico de acuerdo con las características de la estrella con que están conectados mediante la simpatía y sus series. Saber qué agrada y qué desagrada a los demonios es la clave del éxito en la magia: cualquier ama de casa sabe con qué platillo tiene contento a aquel de quien conoce los gustos. ${ }^{45}$

Por simpatía y antipatía se explican también, a grandes rasgos, los amuletos y su fuerza mágica, fuera o dentro de una praxis específica como la de nuestra Simeta que, como ya se apuntó, ante los signos de la presencia de Hécate, recurre al tañido del bronce, a fin de protegerse del furor demoniaco que, por la violencia de su hechizo, se hace presente. Es posible que los laureles del primer verso de nuestro poema tengan esa misma función apotropaica que, sin duda, tiene la roja lana de oveja que se menciona inmediatamente: el demonio, de alguna manera, viene y, en general, está a fuerza; incluso se sabe de algunos casos en que el demonio mismo pide ser liberado, ser despedido mediante la apólisis. Igual, si los poderes superiores se encuentran a gusto: al final del rito hay que despacharlos.

La apólisis se componía de dos elementos: acciones y fórmulas, variables unas y otras de acuerdo con el rito concreto. En la práctica, pues, el mago, o simplemente deponía sus ornamentos, dejaba el cetro y se quitaba la corona, o le quemaba al demonio algo que le fuera repugnante, o le quitaba de la mesa lo que lo retenía agradablemente, o le cambiaba la postura a su medio, o quitaba los signos y símbolos que había puesto o dibujado para la praxis.

la plata, etcétera; sin embargo, esta distribución es fluctuante, y también recoge, para la distribución, las regiones del cielo y las edades de la tierra. Cf. Hopfner, ib. 366 y ss.

${ }^{45}$ Los efectos de alguna práctica concreta dentro de un acto mágico no son de significado unívoco; deben interpretarse circunstancialmente, de acuerdo con los objetivos del mago que, por ejemplo, puede intentar agradar a un demonio, a fin de que le ayude a hacerle mal a un enemigo; pero también para hacerle un mal a su enemigo, puede atentar contra los gustos de ese demonio, etiquetando el hecho con el nombre de aquel a quien quiere dañar... Y eso-es algo muy conocido, incluso actualmente, sobre todo por los políticos. 
Así termina un rito mágico que, basado teóricamente sobre conocimientos teológicos, astrológicos (demonológicos), zoológicos y botánicos estructurados en un sistema de simpatías y antipatías de lo visible con lo invisible, de lo divino con lo terrestre y de lo demoniaco con lo material, era una verdadera techne que conoce los prerrequisitos necesarios de ciertos aconteceres. La magia, pues, puede llamarse ciencia, sólo en cuanto desarrolló sobre una base experimental reglas para una práctica concreta, y explicaciones para los efectos de esas prácticas. ${ }^{46}$ Nuestra Simeta no estaba muy segura de los resultados de su práctica: "ahora voy a embrujarlo con estos filtros", dice en el verso 159, y agrega en seguida: "si aún me angustia"; es decir, si mi hechizo no da resultado, "afirmo reservarle dentro de un arca fuertes venenos, / mortales, que he aprendido de un extranjero de Asiria"...

Así pues, de acuerdo con los preceptos del arte, el rito ya ha terminado por ahora, o hay que terminarlo. Teócrito lo sabe; por una parte, hay que despedir o expulsar a la divinidad, y por la otra, hay que terminar el poema. Su poema, un rito de la palabra, termina ortodoxamente con el rito de hechicería de Simeta. Sería interesante examinar hasta qué punto vale la comparación de un rito mágico y sus efectos, con los efectos de la magia de un discurso; Gorgias decía que la relación que existe entre la fuerza del discurso y la disposición del espíritu, es la misma que se da entre la disposición de los fármacos y la naturaleza de los cuerpos; pues así como unos de los fármacos expulsan del cuerpo a unos humores y otros a otros, y unos calman la enfermedad y otros la vida,-así también, de los discursos, unos afligieron, otros alegraron, otros espantaron, otros transportaron a los oyentes hacia el valor y otros, con cierta mala persuasión, envenenaron y encantaron al espíritu. ${ }^{47}$

${ }^{46}$ Cf. Hopfner, ib. 367, y Zintzen, en Kl. P., s.v. Zauberei, 1461.

${ }^{47}$ Cf. Gorgias, Fragmentos, ib. p. 14. 
¿A qué prácticas recurrió Simeta para despedir a sus demonios? No lo sabemos; cada quien puede imaginarlas. En cuanto a la fórmula, está claro que Teócrito no tuvo necesidad de amenazas; en su contexto, la despedida de Simeta pertenece, creo, al estilo sublime:

Mas tú, llena de encanto, vuelve tus potras hacia el Océano; yo llevaré, señora, mi pena a cuestas, como hasta ahora. ¡Adiós, gran diosa Luna de trono argénteo; adiós, las otras estrellas, que la noche callada siguen cerca del carro!

y uno casi puede imaginarse que misma la luna y otros demonios hubieran querido que el rito se prolongara otro poco, prolongando la noche, prolongando el poema y sus hechizos.

\section{A manera de epílogo}

La magia, en general, nos dice Kleinfeller, era algo permitido en Grecia y en Roma; sólo se convirtió en crimen merced a su unión con ciertas circunstancias peculiares en que se daban

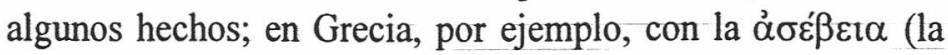
introducción del culto de algún nuevo dios, la desviación de los usos patrios en el ofrecimiento de los sacrificios, la profanación de tumbas), o con la åp $\beta \lambda \omega \sigma i \varsigma$ (el aborto), o con la

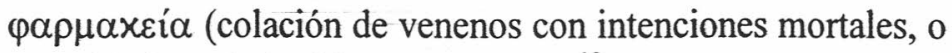
con objetivos de hechicería amorosa). ${ }^{48}$

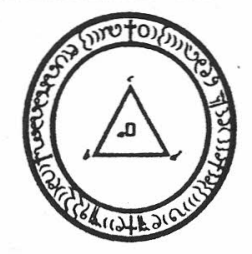

${ }^{48}$ Cf. Kleinfeller, ib. $(14,1), 396,30$ y ss. 